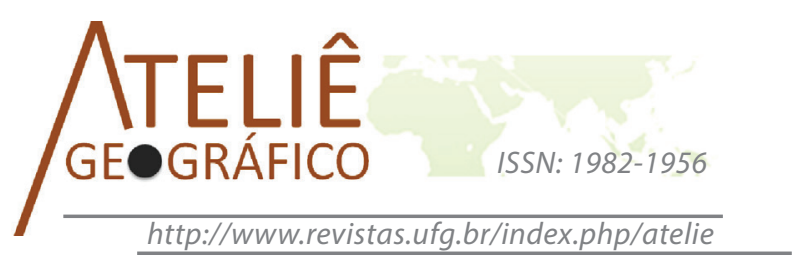

\title{
Produção do espaço urbano pela política habitacional recente (2003-2014): a criação de novos conjuntos habitacionais na Região Metropolitana de Belém
}

\author{
Production of urban space by the recent housing policy \\ (2003-2014): the creation of new estates in the Região \\ Metropolitana de Belém
}

\section{Producción del espacio urbano por la política habitacional reciente (2003-2014): la creación de nuevos conjuntos habitacionales en la Región Metropolitana de Belém}

\author{
Marlon Lima da Silva \\ Universidade Federal do Pará \\ marlon.angelim@yahoo.com.br \\ Janete Marília Gentil Coimbra de Oliveira \\ Universidade Federal do Pará \\ E-mail: jangencom@hotmail.com
}

\begin{abstract}
Resumo
O trabalho discute a produção do espaço urbano, tendo referência o contexto da política habitacional recente (2003-2014) e a construção de novos conjuntos habitacionais. Parte do ano de 2003, momento em que inicia uma nova fase na política habitacional brasileira, avançando até a criação do Programa de Aceleração do Crescimento (PAC) e do Programa Minha Casa Minha Vida (PMCMV). Analisa a produção do espaço urbano, considerando a construção de novos conjuntos habitacionais e suas localizações. Para tanto, utiliza como referência espacial a Região Metropolitana de Belém (RMB). Apesar dos avanços incorporados ao Estatuto das Cidades, em 2001, a política recente tem reforçado uma lógica perversa da localização periférica dos conjuntos habitacionais destinados aos estratos de menor renda, com contribuição direta do PMCMV. Como decorrência, o tecido urbano da RMB tem se estendido precariamente sobre as áreas rurais, num cenário que parece se repetir ao longo das políticas habitacionais, revelando contradições e
\end{abstract}


conflitos na produção do espaço urbano.

Palavras-chave: Espaço Urbano, Política Habitacional, Região Metropolitana de Belém.

\begin{abstract}
The work discusses the production of urban space, having reference to the recent housing policy (2003-2014) and the construction of new housing estates. From the year of 2003, at which point starts a new phase in the Brazilian housing policy, advancing up the creation of the Programa de Aceleração do Crescimento (PAC) and the Programa Minha Casa Minha Vida (PMCMV). It analyzes the production of urban space, considering the construction of new housing estates and their locations. Therefore, uses as a spatial reference the Região Metropolitana de Belém (RMB). Despite advances incorporated in the Statute of the City, in 2001, the recent policy has reinforced a perverse logic of the peripheral location of the housing estates for the lower income strata, with direct contribution of PMCMV. As a result, the urban fabric of the RMB has extended precariously on the rural areas, a scenario that seems to repeat itself over housing policy, revealing contradictions and conflicts in the production of urban space.
\end{abstract}

Keywords: Urban Space, Housing Policy, the Metropolitan Region of Belém.

\begin{abstract}
Resumen
El trabajo analiza la producción del espacio urbano, con referencia a la reciente política habitacional (2003-2014) y la construcción de nuevas viviendas. Parte del año de 2003, punto en que se inicia una nueva etapa en la política habitacional brasileña, avanzando hasta la creación del Programa de Aceleração do Crescimento (PAC) y el Programa Minha Casa Minha Vida (PMCMV). Analiza la producción del espacio urbano, considerando la construcción de nuevas urbanizaciones y sus ubicaciones. Para eso, toma como referencia espacial la Región Metropolitana de Belém (RMB). Pese a los avances incorporados en el Estatuto de la Ciudad, en 2001, la política reciente ha reforzado una lógica perversa de la localización periférica de las viviendas destinadas a los estratos de menor renta, con la contribución directa de PMCMV. Como resultado, el tejido urbano del RMB se ha ampliado precariamente en las zonas rurales, un escenario que parece repetirse sobre la política de vivienda, revelando las contradicciones y conflictos en la producción del espacio urbano.

Palabras clave: Espacio Urbano, Política Habitacional, Región Metropolitana de Belém.
\end{abstract}

\title{
Introdução
}

A habitação constitui uma das necessidades humanas básicas, de tal modo que o Estado, por meio da execução de políticas habitacionais, viabiliza ações para a provisão de moradias a diferentes segmentos sociais, indo das famílias de renda mais baixa às de renda média alta. No entanto, a construção de habitações não é uma tarefa simples, pois a cada processo produtivo implica a necessidade de aquisição de um novo terreno, dependendo, assim, intimamente do solo que além de não poder ser reproduzido, 
está sujeito a uma série de fatores que encarecem o seu preço como, por exemplo, a localização.

A produção de habitações no interior das cidades representa quase que o espelho da diferenciação social no espaço. Edifícios luxuosos, condomínios destinados às classes médias e altas, conjuntos habitacionais e ocupações irregulares constituem exemplos dessa diferenciação. Essas formas de habitação se concentram em determinados setores das cidades, configurando áreas com certa homogeneidade interna. Desse modo, a localização e o padrão construtivo da habitação variam diretamente com poder aquisitivo da demanda, traduzindo espaços específicos que revelam a lógica conflituosa da produção do espaço urbano.

No Brasil, historicamente as políticas habitacionais têm sido alvo de muitas críticas que vão desde a construção e o acabamento das unidades habitacionais até a sua localização. Essas políticas estão intimamente relacionadas à produção do espaço urbano, isso porque a construção de conjuntos habitacionais tem contribuído para a extensão do tecido urbano de muitas cidades, com destaque para as pertencentes aos aglomerados metropolitanos. Diante disso, as políticas habitacionais e a construção de conjuntos habitacionais constituem elementos de grande relevância para se pensar a produção do espaço urbano.

O presente trabalho discute a produção do espaço urbano tendo com base a reprodução de conjuntos habitacionais. Como recorte temporal (2003-2014), parte-se do momento em que inicia uma nova fase na política habitacional brasileira, com a criação do Ministério das Cidades e a instituição do Plano Nacional de Habitação (PLANHAB) (BONDUKI, 2008). A essa fase são acrescentados, também, a elaboração do Programa de Aceleração do Crescimento (PAC) e do Programa Minha Casa Minha Vida (PMCMV) que emergiram na segunda metade dos anos 2000, prevendo a construção de milhares de unidades habitacionais em todo país. O recorte espacial utilizado se reporta à Região Metropolitana de Belém (RMB), buscando analisar como tal política tem produzido o espaço urbano por meio da construção de conjuntos habitacionais.

Nesse entendimento, a localização dos conjuntos representa variável chave, já que por meio dela é possível analisar os processos e as práticas espaciais, bem como as estratégias dos principais agentes delimitados pela política habitacional, elucidando uma série de contradições e conflitos.

Diante do exposto, o presente trabalho está estruturado em quatro momentos: inicialmente é realizado um breve debate sobre habitação e espaço urbano, revelando as interações entre esses conceitos e destacando os conjuntos habitacionais como elemento de análise da produção do espaço urbano; o segundo momento apresenta resumidamente a trajetória seguida pela política habitacional brasileira e seus efeitos sobre o espaço urbano, a partir da construção de conjuntos habitacionais; em seguida, o debate foca na política habitacional recente, apresentando sua natureza e caracterização geral com base nos diferentes programas e fundos de financiamento instituídos e; por fim, realiza uma 
breve análise empírica, enfocando as materializações dessa política recente, a partir da construção de novos conjuntos habitacionais na RMB.

\section{Interações entre habitação, espaço urbano e criação de conjuntos habitacionais}

Um simples passeio pelas grandes cidades revela mesmo aos observadores menos atentos a presença de uma série de usos como, por exemplo, residencial, comercial, serviços, etc. Dentre esses, não resta dúvida de que o residencial é notadamente o uso mais presente no contexto geral, ainda que em determinadas áreas outros usos predominem. Isso porque, morar, assim como se alimentar e vestir, constitui uma das necessidades básicas dos indivíduos e, independentemente do local (na cidade pequena, média, metrópole ou no campo), de alguma forma é preciso morar, ainda que seja de baixo de um viaduto, num conjunto habitacional, condomínio de luxo, etc. (MARICATO, 2009; RODRIGUES, 2003).

De fato, a habitação exerce importância qualitativa e quantitativa no conjunto do ambiente construído, sobretudo, dos aglomerados metropolitanos. Historicamente as políticas habitacionais têm sido direcionadas para esses espaços, a partir da construção de uma série de conjuntos habitacionais que, por sua vez, constituem importantes indicadores da produção do espaço urbano. Tal compreensão, no entanto, requer a elucidação de alguns conceitos-chaves, dentre os quais estão os seguintes: "casa", "moradia", "habitação" e "conjuntos habitacionais".

Os termos casa, moradia e habitação, apesar de soarem aparentemente como sinônimos, apresentam certas características peculiares. De acordo com Martucci (1990, p. 202), enquanto a "casa" expressa muito mais o "ente físico", ou melhor, a forma visível propriamente dita, a "moradia" se caracteriza como sendo a casa mais os "hábitos de uso da casa", ou seja, o "modo de vida dos usuários". A "habitação", por sua vez, seria representada como a integração da casa e da moradia ao espaço urbano.

Nessa imbricação, os conjuntos habitacionais podem ser conceituados como uma forma de habitação particular, caracterizada, de modo geral, por conter um conjunto de casas e/ou lotes, inicialmente padronizados, de construção do tipo vertical (apartamentos) ou horizontal, oriundas ou não da ação do Estado via políticas habitacionais. Essas políticas variam ao longo do tempo, destinando-se às diferentes demandas e materializando-se numa gama diversa de conjuntos habitacionais, sendo o espaço a condição e o meio fundamental de reprodução.

A habitação, apesar de consistir em um bem indispensável para a reprodução da vida, quando é considera sua produção capitalista, como qualquer outro bem, a demanda é constituída apenas da parcela solvável (VILLAÇA, 1986). O que se percebe, diante disso, é a emergência de uma situação crítica quanto ao acesso à habitação, haja vista que "aqueles que não têm renda suficiente para adquirir uma determinada mercadoria estão excluídos da demanda, não obstante dela necessitar” (PECHMAN E RIBEIRO, 1985, p. 9). 
Além disso, cabe lembrar que a produção habitacional está intimamente atrelada ao solo e este não pode ser reproduzido, fato que acaba encarecendo o preço final dos imóveis. Tudo isso têm produzido contradições que se materializam no espaço urbano, a partir de práticas e processos que se evidenciam nas ações dos principais agentes envolvidos com construção de conjuntos habitacionais.

Segundo Corrêa (2007, p.68), as práticas espaciais representam “(...) ações espacialmente localizadas, engendradas por agentes sociais concretos, visando a objetivar seus projetos específicos". No caso da construção dos conjuntos, essas práticas se manifestam nas localizações específicas no interior das cidades.

Os agentes delimitados no âmbito das políticas habitacionais buscam diferentes áreas no interior dos aglomerados metropolitanos para a construção desses conjuntos. A escolha da localização, no entanto, não ocorre de forma aleatória, há uma lógica que preside a ação. Essa lógica está relacionada com a natureza das políticas habitacionais e com os interesses dos diferentes agentes envolvidos na produção dos conjuntos.

Conjuntos habitacionais situados em áreas bem infraestruturadas apresentam unidades habitacionais com preços elevados se comparados aos conjuntos localizados em outras áreas. Nessa lógica conflituosa, não resta alternativa aos estratos de menor renda, de modo que excetuando a moradia em conjuntos habitacionais periféricos (quando atendidos pelas políticas habitacionais), esses segmentos são induzidos a morar em ocupações e favelas. De fato, as políticas habitacionais têm atendido insatisfatoriamente a esses estratos, direcionando-se, assim, sobretudo, para o atendimento da chamada demanda "solvável", ou seja, aqueles que podem pagar pelo alto preço da habitação.

$\mathrm{Na}$ busca pelas "melhores" localizações, historicamente os conjuntos habitacionais destinados aos segmentos de menor renda têm sido construídos em locais afastados da malha urbana, distantes dos setores de comércio e serviços, muitas vezes em áreas rurais, onde o preço da terra é mais baixo. Infraestrutura viária precária, insuficiência de transporte coletivo e distância dos postos de trabalho são apenas alguns problemas decorrentes.

Essas ações repetidas ao longo das políticas têm gerado a extensão precária do tecido urbano, sobretudo, nos aglomerados metropolitanos que são os espaços que mais concentram a produção desses conjuntos. Essa extensão do tecido urbano se caracteriza como um amplo processo espacial, isto é, "um conjunto de forças atuando ao longo do tempo, viabilizando localizações, relocalizações e permanência de atividades e população sobre o espaço da cidade" (CORRÊA, 2007, p. 68). A esse processo maior, adicionamse outros como, por exemplo, o processo de segregação, emergindo da "capacidade que cada grupo social tem de pagar pela residência que ocupa" (CORRÊA, 1989, p.59).

Nesse sentido, a existência da propriedade privada do solo "significa a divisão e a parcelarização da cidade" (CARLOS, 2007, p. 27), de tal modo que "o acesso à habitação e aos meios de consumo coletivo serão desiguais e diferenciados segundo a camada social que se localizará e morará de modo diferenciado na cidade" (SILVEIRA, 2003, p. 36-37). De fato, as políticas habitacionais têm revelado distintamente essa 
lógica perversa no interior dos aglomerados metropolitanos, com a construção de série de conjuntos habitacionais que expressam uma gama de conflitos na produção do espaço urbano. A seguir, realiza-se uma breve discussão sobre a trajetória da política habitacional brasileira, com o objetivo de introduzir e situar a análise da produção do espaço urbano no contexto mais recente.

\section{A política habitacional brasileira produzindo o espaço urbano: breve trajetória}

Não resta dúvida de que na história da ação do poder público na provisão de conjuntos habitacionais no Brasil, o período compreendido entre 1964 e 1986 constitui um marco significativo de uma série de estudos que se voltaram e se voltam ao entendimento da natureza e das implicações da política habitacional. Trata-se do período de atividade do Banco Nacional de Habitação (BNH).

É válido ressaltar, no entanto, que as origens das intervenções do poder público na construção de habitações populares no Brasil remontam ao final do século XIX, durante a República Velha (1989-1930). De um modo geral, sabe-se que a amplitude e os desdobramentos desse período foram bastante modestos, de modo que "as iniciativas tomadas pelos governos (...) no sentido de produzir habitação ou de regulamentar o mercado de locação residencial são praticamente nulas” (BONDUKI, 1994, p. 712).

De fato, o BNH se constituiu no principal produtor de habitações em toda história da política habitacional brasileira. Os segmentos atendidos por essa política foram divididos em três: a) mercado popular (famílias com renda mensal de até três salários mínimos limite posteriormente ampliado para cinco); b) mercado econômico (famílias com renda mensal entre três e seis salários mínimos) e; c) mercado médio (famílias com renda mensal mínima de seis salários mínimos).

A maior parte dos recursos destinou-se às faixas do mercado econômico e médio, o que foi propriamente de encontro aos objetivos formalizados pelo Estado, considerando as diretrizes da referida política que se dizia comprometida prioritariamente com as faixas de menor renda (AZEVEDO e ANDRADE, 1982). Essa é apenas uma das inúmeras críticas tecidas à política habitacional do período, dentre as quais se acrescenta, também, a localização periférica e o padrão arquitetônico dos conjuntos.

Com a extinção do BNH e a passagem de suas funções para Caixa Econômica Federal (CEF), em 1986, a política habitacional se desestruturou, dentre outras coisas, pela perda do órgão que centralizava praticamente todas as estratégias de ação direcionadas à produção habitacional na escala nacional. Nesse contexto, abriu-se uma nova fase da política habitacional brasileira, "caracterizada por uma forte confusão institucional provocada por constantes reformulações nos órgãos responsáveis” (BOTEGA, 2008, p. 11). Trata-se do período denominado de pós- $B N H$ - praticamente duas décadas sem uma política habitacional definida.

No entanto, esse vazio começou a ser preenchido a partir de 2003 com a criação do Ministério das Cidades. De 2003 até os dias atuais, já é possível afirmar a ocorrência 
de uma nova fase na política habitacional brasileira. Essa fase foi marcada inicialmente pela incorporação de um vasto aparato jurídico (da Constituição de 1988 à aprovação do Estatuto das Cidades $^{1}$ ) que culminou com a criação do Ministério das Cidades e a elaboração da nova Política Nacional de Habitação (PNH), lançada em 2004, e do Plano Nacional de Habitação (PLANHAB), em 2008.

Além disso, foi lançado o Programa de Aceleração do Crescimento (PAC) em 2007, prevendo, dentre outras coisas, a utilização de R \$ 11,6 bilhões para a urbanização de favelas e R\$ 44,3 bilhões para novas moradias. Em 2009, foi lançado o Programa Minha Casa Minha Vida (PMCMV), prevendo inicialmente a utilização de R \$ 34 bilhões para a construção de 1 milhão de moradias, em diferentes faixas de financiamento (MARICATO, 2011).

Todas essas mudanças ocorridas a partir do início dos anos 2000 sinalizaram um cenário otimista para a produção habitacional do país, sobretudo, com a retomada dos financiamentos via Fundo de Garantia por Tempo de Serviço (FGTS) e Sociedade Brasileira de Poupança e Empréstimo (SBPE). Diante disso, incluindo os subsídios do Orçamento Geral da União (OGU), foram investidos R\$ 68,5 bilhões em habitação entre os anos de 2003 e 2009 através de uma série de ações como aquisição, reforma e ampliação de unidades habitacionais, aquisição de material de construção, produção de lotes urbanizados e urbanização de assentamentos precários. Merece destaque o aumento significativo dos investimentos da SBPE que, se em 2002 financiou 28.905 unidades habitacionais em todo Brasil, no ano de 2009 teve 293.522 unidades financiadas para os segmentos da chamada classe média ${ }^{2}$ (MARICATO, 2011).

Nesse percurso histórico da política habitacional brasileira, várias críticas têm sido direcionadas à sua forma de atuação, destacando-se as seguintes: atendimento insuficiente das demandas mais necessitadas, construção de grandes conjuntos habitacionais em localizações periféricas, muitas vezes em áreas rurais não integradas à malha viária, padrão construtivo e urbanístico massivo, não respeitando as características regionais, precariedade da habitação destinada à demanda popular, infraestrutura insuficiente no entorno, etc.

De fato, no Brasil, a maioria dos conjuntos habitacionais destinados aos estratos de menor renda foi e vem sendo produzida em locais originalmente periféricos (por vezes nos limites das áreas urbanas dos aglomerados metropolitanos) através de práticas e processos espaciais que marcaram os diferentes interesses dos agentes delimitados pelas políticas habitacionais, tendo grande peso na extensão dos tecidos urbanos.

1. "O Estatuto da Cidade é uma Lei Federal (10.257/01) que regulamentou e desenvolveu o capítulo Da Política Urbana da Constituição Federal (artigos 182 e 183), estabelecendo como deve ser elaborada a política urbana em todo o país. Seu objetivo é possibilitar que as cidades brasileiras possam crescer de forma mais ordenada, proteger o meio ambiente e garantir os direitos urbanos fundamentais, como a moradia digna e os transportes sustentáveis" (MINISTÉRIO DAS CIDADES, 2006, p. 4)

2. Esse aumento expressivo na produção habitacional do mercado privado para a classe média ocorreu também em função de uma série de leis que tiveram como resultado o fato de os investidores terem garantida a "alienação fiduciária", ou seja, o direito de retomada do imóvel durante o não pagamento, processo que era lento e passou a ter uma tramitação muito mais veloz (MARICATO, 2011). 
Nesse bojo, sabe-se que a "interferência do Estado, por intermédio do Banco Nacional da Habitação (BNH) ajudou a criar um modelo urbano disperso e extenso, que tende a se reproduzir" (SANTOS, 1994, p. 67). Esse modelo pode ser visto em várias metrópoles brasileiras. O exemplo mais notável, talvez, seja a cidade de São Paulo, com a produção do Complexo Cidade Tiradentes, "maior concentração de conjuntos habitacionais do Brasil e da América Latina” (OTERO, 2009, p.16) e, também, na cidade do Rio de Janeiro, onde se construiu um grande conjunto habitacional denominado Cidade de Deus ${ }^{4}$. Ambos foram construídos em função do deslocamento de populações atingidas por obras públicas nas áreas centrais ou próximas ao centro, marcando, grosso modo, um processo de segregação imposta pelo Estado.

Longe de se discutir ou até mesmo apresentar a natureza da expansão do tecido urbano em diferentes metrópoles brasileiras via construção de conjuntos habitacionais, o que se busca ressaltar é o modo como esses conjuntos estão intimamente relacionados ao processo de produção do espaço urbano, com diferentes agentes e práticas espaciais, podendo revelar a natureza de uma série de conflitos em torno do ambiente construído, sobretudo, a extensão do tecido urbano para as periferias metropolitanas.

Do mesmo modo, porém, em intensidade distinta, esse padrão parece se repetir atualmente com o PMCMV, materializando-se na construção de conjuntos habitacionais nas periferias dos aglomerados metropolitanos. Os avanços na legislação urbanística, com o desenvolvimento do Estatuto das Cidades, têm se revelado pouco presente na prática, permitindo, com isso, a quase que repetição dos problemas evidenciados ao longo da trajetória da política habitacional no país.

Considerando a produção de novos conjuntos habitacionais e a estrutura das diferentes frentes de ação da política habitacional recente já é possível analisar os efeitos espaciais oriundo desse novo momento. Tais efeitos se traduzem no espaço urbano a partir da análise dos conjuntos habitacionais.

\section{Considerações sobre a política habitacional recente (2003-2014)}

Anterior ao debate sobre a produção do espaço urbano pela política habitacional recente faz-se necessário inicialmente compreender e discutir como essa política tem se estruturado. Esse exercício permite o reconhecimento de seus principais agentes, além de revelar a natureza dos diferentes programas que emergiram a partir de 2003 .

3. "Cidade Tiradentes abriga o maior complexo de conjuntos habitacionais da América Latina, com cerca de 40 mil unidades, a maioria delas, construídas na década de 1980 pela COHAB (Companhia Metropolitana de Habitação de São Paulo), CDHU (Companhia de Desenvolvimento Habitacional e Urbano do Estado de São Paulo) e por grandes empreiteiras, que inclusive aproveitaram o último financiamento importante do BNH (Banco Nacional da Habitação), antes de seu fechamento" (www.prefeitura.sp.gov.br).

4. "Na década de 1960, com a transformação do Distrito Federal em Estado da Guanabara, o Governador Carlos Lacerda implementou uma política de remoção das favelas situadas na zona sul da Cidade, no entorno da Lagoa Rodrigo de Freitas, além de algumas outras, para isso autorizando a construção de grande conjunto habitacional na baixada de Jacarepaguá. Surgiu assim a Cidade de Deus.Construída pela COHAB e financiada pelo BNH". (www.portalgeo.rio.rj.gov.br). 
Como apresentado, a nova Política Nacional de Habitação (PNH) começou a ser desenhada a partir do acúmulo de uma série de avanços institucionais que vão desde a Constituição de 1988, passando pela aprovação do Estatuto das Cidades até a criação do Ministério das Cidades, em 2003, sendo este, o órgão coordenador, gestor e formulador da Política Nacional de Desenvolvimento Urbano no qual a nova PNH está inclusa. A estruturação da política ocorreu através da criação do Sistema Nacional de Habitação (SNH), composto por dois subsistemas: Sistema Nacional de Habitação de Interesse Social (SNHIS) e Sistema Nacional de Habitação de Mercado (SNHM), sendo o primeiro voltado às famílias com rendimento de até três salários mínios e o segundo às famílias com rendimentos superiores que podem ser atendidas pelo mercado (BONDUKI, 2009). Ao longo da análise empírica elegeu-se trabalhar com o SNHIS, sobretudo, pela ausência de dados no que se refere ao SNHM.

O SNHIS foi criado pela Lei 11.124/2005, juntamente com o Fundo Nacional de Habitação de Interesse Social (FNHIS), sendo este um de seus componentes fundamentais, além do FGTS, do Fundo de Amparo ao Trabalhador (FAT), e também, os recursos de fundos para programas específicos como o Fundo de Arrendamento Residencial (FAR) e o Fundo de Desenvolvimento Social (FDS). Sabe-se que o FNHIS:

centraliza todos os recursos orçamentários da União, ou administrados por ela, disponíveis para a moradia de baixa renda. Alimentam esse fundo, além das dotações do OGU classificadas na função habitação, os recursos do FAS (Fundo de Apoio ao Desenvolvimento Social), os recursos provenientes de empréstimos externos e internos para programas de habitação, e outras receitas patrimoniais e operacionais, além de doações e contribuições variadas (BONDUKI, 2009, p. 7).

O acesso aos recursos do FNHIS pelos entes federativos foi condicionado à adesão ao SNHIS por meio da assinatura do chamado termo de adesão no qual os municípios, estados e Distrito Federal se comprometiam na criação de fundos, conselhos e Planos Locais de Habitação de Interesse Social (PLHIS) "de forma a garantir sustentabilidade, racionalidade e, sobretudo, a participação democrática na definição e implementação dos programas e projetos" (CARDOSO et all, 2011, p. 2).

O estado do Pará aderiu ao FNHIS em 2007 e a partir da Lei Estadual 7.087/08 criou o Sistema Estadual de Habitação de Interesse Social (SEHIS) e seu órgão gestor - o Conselho Estadual das Cidades (ConCidades/PA). Foi criado, também, o Fundo Estadual de Habitação de Interesse Social (FEHIS) e seu Conselho Gestor (GOVERNO DO ESTADO DO PARÁ, 2009). Em 2009 foi criado o Plano Estadual de Habitação de Interesse Social (PEHIS), em sintonia com PLANHAB, marcando o contexto norteador da nova Política Nacional de Habitação.

O termo de adesão no Pará foi assinado por 96\% dos municípios, 43\% efetivaram fundo e conselho de habitação e 51\% acessaram recursos para a elaboração do plano local até julho de 2010 (HOLANDA, 2011). No entanto, se o interesse em aderir ao SNHIS foi amplo, a efetivação no acesso aos recursos do FNHIS para a construção de 
conjuntos habitacionais se revelou restrita em decorrência da baixa capacidade de gestão dos municípios que não conseguiram superar as exigências técnicas e burocráticas da CEF para a liberação dos recursos. Na análise empírica, essa realidade se expressou quando foram identificados apenas dois conjuntos habitacionais oriundos de recursos do FNHIS.

Considerando que o horizonte do PLANHAB é o ano de 2023, articulando-se com os Planos Plurianuais (PPAs) (2011, 2015, 2019, 2023), ainda não é possível tecer uma avaliação detalhada. No entanto, já é possível observar a ocorrência de um embate entre programas federais com o lançamento do PAC e principalmente do PMCMV que inicialmente não dialogavam com a sistemática geral do PLANHAB, injetando recursos habitacionais à margem do SNHIS e impossibilitando a sua utilização democrática. Ambos dispensam os espaços de discussões promovidos pelo Ministério das Cidades, como a Conferência das Cidades, onde em 2004 foi criado o Conselho das Cidades (Concidades), marcando um momento de gestão democrática da política habitacional (CARDOSO, 2009, HOLANDA, 2011).

De fato, grande parte dos avanços teoricamente incorporados na nova Política Nacional de Habitação foram diluídos, sobretudo, com o PMCMV. Desse modo, o Estatuto das Cidades se pulverizou, juntamente com a possibilidade de garantir a função social da propriedade urbana por meio da aplicação dos instrumentos de controle urbanístico de inclusão social e a gestão democrática, contidos nos Planos Diretores Municipais (PDM).

A comparação entre o PAC e o PMCMV já mostra sinais claros das contradições que vêm permeando a nova Política Nacional de Habitação:

O PAC 1, de 2007 [...] dialoga mais com o desenvolvimento urbano do que o pacote habitacional lançado pelo governo federal, o PMCMV, de 2009 [..] a recuperação de áreas urbanas degradadas, prevista no PAC 1, assegura, de fato, uma condição urbana saudável exatamente para os mais pobres, consolidando sua localização e também relações já construídas com o entorno [...] Já o PMCMV retoma a política habitacional com interesse apenas na quantidade de moradia, e não na sua fundamental condição urbana [...] Interesses privados desarticulados podem definir a localização de maior parte do 1 milhão de moradias do PMCMV, já que dificilmente as prefeituras e câmaras municipais, além da própria Caixa Econômica Federal, o grande unificador da aprovação dos projetos, deixarão de atender apelos para a aprovação de uma construção de porte. Pelo menos essa não é a tradição no Brasil (as localizações de mercado são melhores, pois se designam à venda. As outras não) (MARICATO, 2011, p. 67-69).

Nesse debate, não se pode desconsiderar que o PAC e o PMCMV nasceram com propostas e finalidades próprias. O PAC foi instituído em 2007 e buscava retomar grandes obras de infraestrutura nos setores de logística (ferrovias, portos, aeroportos), energia (geração e distribuição, petróleo, gás natural, etc.) e infraestrutura social (saneamento, habitação, etc.), praticamente abandonadas desde a década de 1980 pelo governo federal. 
Trata-se de um amplo programa destinado fundamentalmente ao aumento do Produto Interno Bruto (PIB), por meio de investimentos público e privados em grandes obras de infraestrutura na qual a habitação está inclusa tanto na produção de novas moradias, quanto na urbanização de favelas. Na habitação, o PAC atuou, sobretudo, nas grandes cidades, por meio da urbanização de áreas carentes do ponto de vista infraestrutural.

$\mathrm{O}$ PMCMV emergiu num panorama diferenciado que esteve relacionado à crise financeira internacional de 2008. Com a alegação de combater a referida crise, o governo federal lançou um grande pacote habitacional denominado de PMCMV, buscando "claramente impactar a economia através dos efeitos multiplicadores gerados pela indústria da construção" (CARDOSO E ARAGÃO, 2013, p. 35). Inicialmente, o Programa se comprometeu com a construção de 1 milhão de novas unidades habitacionais, posteriormente acrescida de mais 2 milhões pelo PMCMV 2 até 2014.

Considerando o volume de subsídios previstos no lançamento do pacote é possível ter uma dimensão dos recursos destinados ao PMCMV, de modo que "34 bilhões de reais, era de fato inédito na história do país: nem mesmo o BNH dirigiu tantos recursos à baixa renda numa única operação" (FIX, 2011, p. 140). A origem desses recursos foram OGU (25,5 bilhões) e FGTS (7,5 bilhões), sendo previsto ainda 1 bilhão para obras de infraestrutura urbana complementar pelo Banco Nacional de Desenvolvimento Econômico e Social (BNDES).

Não é por acaso que o PMCMV vem sendo alvo de uma série de estudos, de diferentes frentes, dente as quais se destacam as análises referentes aos impactos nas cidades, ao padrão construtivo dos conjuntos e à apropriação dos recursos pelas principais construtoras e incorporadoras (CARDOSO ET all, 2011; CARDOSO E ARAGÃO, 2013; FIX, 2011; SHIMBO, 2010).

Trata-se de um programa que chega a se assemelhar em alguns aspectos à política do $\mathrm{BNH}$, sobretudo, no que se refere à produção em massa de conjuntos habitacionais e à segmentação do mercado em diferentes faixas de financiamento. Assim como no BNH, o PMCMV foi dividido em três faixas: faixa 1 - 0 a 3 salários mínimos, faixa 2 - 3 a 6 salários mínimos e faixa 3 - 6 a 10 salários mínimos. Cada faixa apresenta um tipo de financiamento diferenciado.

A compreensão das materializações do PMCMV requer a identificação geral de sua estrutura de operacionalização que além das referidas faixas, subdivide-se em quatro subprogramas: Programa Nacional de Habitação Urbana (PNHU), Programa Nacional de Habitação Rural (PNHR), PMCMV Entidades e PMCMV abaixo de 50.000 habitantes.

O Quadro 1 sintetiza a estrutura de operacionalização PMCMV, com as faixas, os financiamentos e os principais agentes que vêm atuando na produção habitacional. 
Quadro 1. Estrutura de operacionalização do Programa Minha Casa Minha Vida

\begin{tabular}{|c|c|}
\hline $\begin{array}{l}\text { Faixa 1: de } 0 \text { a } 3 \text { Salários } \\
\text { Mínimos } \\
\text { Execução via Fundo de } \\
\text { Arrendamento Residencial (FAR) }\end{array}$ & $\begin{array}{l}\text { A produção é "por oferta", o que significa que a } \\
\text { construtora define o terreno e o projeto, aprova-o } \\
\text { junto aos órgãos competentes e vende integralmente o } \\
\text { que produzir para a CEF, sem gastos de incorporação } \\
\text { imobiliária e comercialização, e sem risco de } \\
\text { inadimplência dos compradores ou vacância das } \\
\text { unidades. A CEF define o acesso às unidades a partir } \\
\text { de listas de demanda, elaboradas pelas prefeituras. } \\
\text { Os municípios têm como incumbência cadastrar as } \\
\text { famílias com rendimento de } 0 \text { a } 3 \text { salários mínimos, } \\
\text { além da participação por meio da doação de terrenos, } \\
\text { isenção tributária e desburocratização nos processos de } \\
\text { aprovação e licenciamento e também na flexibilização } \\
\text { das normas urbanísticas para permitir aumentar os } \\
\text { índices de utilização do solo nos empreendimentos do } \\
\text { PMCMV. }\end{array}$ \\
\hline $\begin{array}{l}\text { Faixa 1: de } 0 \text { a } 3 \text { Salários } \\
\text { Mínimos } \\
\text { Através do PMCMV Entidades. } \\
\text { Segue-se o mesmo modelo } \\
\text { anteriormente adotado no } \\
\text { Programa Crédito Solidário: } \\
\text { Financiamento através do Fundo } \\
\text { de Desenvolvimento Social (FDS). }\end{array}$ & $\begin{array}{l}\text { Entidades sem fins lucrativos (cooperativas, } \\
\text { associações de moradia, etc.) apresentam projetos } \\
\text { à CEF, que podem ser (ou não) em parceria com } \\
\text { estados e municípios. A CEF efetua as análises e, } \\
\text { após sua conclusão, envia ao Ministério das Cidades } \\
\text { a relação de projetos para seleção. O Ministério das } \\
\text { Cidades faz a seleção e reencaminha para a CEF que } \\
\text { aguarda o envio, pela entidade selecionada, da lista de } \\
\text { beneficiários a serem atendidos. A CEF efetua a análise } \\
\text { de enquadramento dos beneficiários indicados, contrata } \\
\text { a operação e acompanha a execução da obra. }\end{array}$ \\
\hline $\begin{array}{l}\text { Faixa } 2 \text { e 3: de } 3 \text { a } 10 \text { Salários } \\
\text { Mínimos } \\
\text { Financiamento via Fundo de } \\
\text { Garantia por Tempo de Serviço } \\
\text { (FGTS) }\end{array}$ & $\begin{array}{l}\text { As construtoras/ incorporadoras apresentam projetos } \\
\text { de empreendimentos à CEF, que realiza pré- } \\
\text { avaliação e autoriza o lançamento e comercialização. } \\
\text { Após a conclusão da análise e comprovação da } \\
\text { comercialização mínima exigida, é assinado o Contrato } \\
\text { de Financiamento à Produção. A comercialização é } \\
\text { feita pelas construtoras ou através dos "feirões" da } \\
\text { Caixa, havendo a possibilidade de que os pretendentes à } \\
\text { aquisição consigam uma carta de crédito na Caixa para } \\
\text { ir ao mercado buscar uma moradia para aquisição. }\end{array}$ \\
\hline
\end{tabular}


Municípios com menos de $\mathbf{5 0 . 0 0 0}$ hab. "sub 50".

O financiamento é operado através de Agentes Financeiros Privados (e não pela Caixa Econômica).
A operacionalização dessa modalidade é feita via oferta pública de recursos. As instituições financeiras se inscrevem e são selecionadas pela CEF, que em conjunto com o MCidades, define e publica o volume de recursos destinado a cada Agente Financeiro, ficando cada agente financeiro responsável por uma determinada região. O MCidades também recebe, via site, o cadastro de propostas dos entes federados, que são então selecionadas tendo como referência o déficit habitacional municipal. Os agentes financeiros são os responsáveis pela análise de risco e contratação das propostas selecionadas, e por manter o MCidades informado sobre as contratações.

Fonte: Cardoso e Lago, 2013. Adaptado pelos autores.

Considerando a trajetória recente da nova Política Nacional de Habitação pode-se observar que os três grandes planos elaborados apresentam pontos destoantes quanto à concepção e finalidade. Se de um lado o PLANHAB absorveu boa parte dos avanços institucionais previstos no Estatuto das Cidades quanto à gestão democrática $\mathrm{e}$ à função social da propriedade, por outro lado, a partir do PAC, mas com maior força no PMCMV, os instrumentos de controle social foram negligenciados, dispensando os espaços de discussão democrática, sob o principal pretexto de "agilização dos processos de alocação e utilização de recursos, necessária, em um primeiro momento, para viabilizar os objetivos econômicos do programa (CARDOSO E ARAGÃO, 2013, p. 63)". São contradições que emergem do PMCMV, comprometido ao mesmo tempo com objetivos econômicos e sociais, prevendo as ações amplas que são deixadas ao livre jogo da iniciativa privada que, como tal, age de modo a obter sempre maiores lucros, trazendo à tona antigas questões sobre a localização periférica de grandes conjuntos habitacionais, tão criticadas em vários estudos desde o período do $\mathrm{BNH}$.

Diante desse quadro geral que marca a nova PNH é válido identificar as principais práticas e os processos espaciais que vem marcando a produção do espaço urbano via reprodução de conjuntos habitacionais. Para tanto, utiliza-se como referência empírica de análise a Região Metropolitana de Belém (RMB), identificando as materializações dos diferentes programas e fundos representativos da política habitacional recente (FNHIS, PAC, PMCMV).

\section{Materializações da política habitacional recente (2003-2014) na RMB}

A RMB é composta atualmente pelos seguintes municípios: Belém, Ananindeua, Marituba, Benevides, Santa Bárbara do Pará, Santa Isabel do Pará e Castanhal. A sua principal aglomeração de comércio e serviços está presente no interior da chamada 
Primeira Légua Patrimonial de Belém - área de uma légua concedida por meio de Carta de Sesmaria à municipalidade, ainda no século XVII, iniciando oficialmente o patrimônio municipal de Belém (SARGES, 2002).

Para a análise das materializações da política habitacional recente é válido partir de uma breve caracterização quanto à estruturação atual da RMB, considerando a presença de áreas rurais e urbanas, conforme aponta a Figura 1.

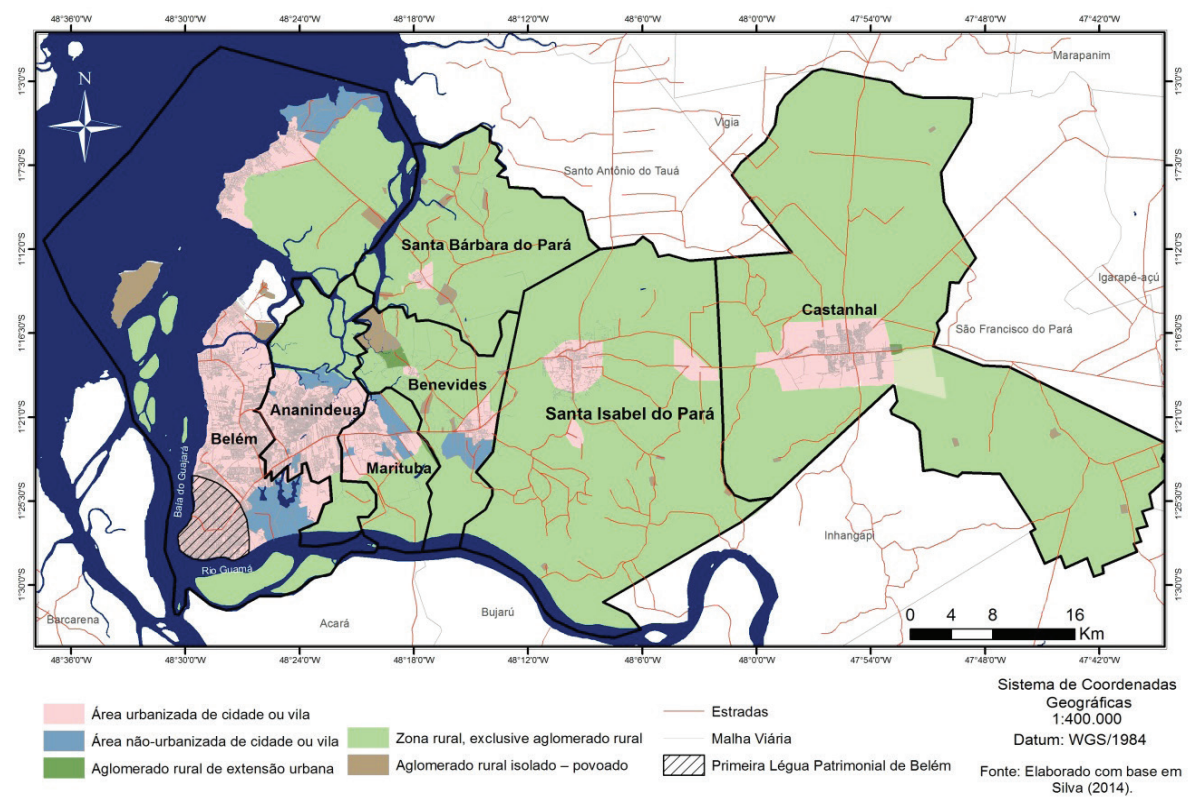

Figura 1. Relação das áreas rurais e urbanas na Região Metropolitana de Belém. Fonte: IBGE, 2010; Elaborado pelos autores.

Nota-se a predominância de áreas rurais sobre as urbanas, além da concentração da mancha urbana contínua adensada no núcleo metropolitano (Belém), em Ananindeua e Marituba, ocorrendo de forma descontínua nos demais municípios. Destaca-se, também, a presença de uma vasta área urbana no Município de Castanhal que foi integrado recentemente (2013) à RMB, compondo uma espécie de sub-centro no atual contexto metropolitano.

Apesar da predominância de áreas rurais, ressalta-se que a partir da década de 1960 a mancha urbana vem se expandindo de forma acelerada, num processo em que a construção de conjuntos habitacionais e, também, de outras formas de habitação (como ocupações e condomínios horizontais fechados) assume papel de destaque. A política do $\mathrm{BNH}$, com a construção de grandes conjuntos habitacionais afastados do núcleo urbano, 
contribuiu significativamente para esse processo, sobretudo, para a junção das malhas urbanas entre Belém e Ananindeua.

No período de funcionamento do BNH (1964 a 1986) os conjuntos destinados às famílias de renda média e alta foram construídos inicialmente no interior e/ou nas proximidades da principal área de aglomeração de comércio e serviço (Primeira Légua Patrimonial). Porém, os conjuntos voltados para as demandas populares foram construídos em locais afastados, considerados, muitas vezes como rurais (SILVA, 2014). Tudo isso tem traduzido a lógica perversa da produção do espaço urbano, de tal modo que aos mais necessitados são destinados os terrenos mais baratos para a construção dos conjuntos.

Apesar dos avanços com a Constituição Federal de 1988 e com a criação do Estatuto das Cidades, muito pouco tem sido feito para a mudança desse quadro no âmbito das políticas habitacionais. Na verdade, esse cenário parece se repetir no atual contexto, sobretudo, quando se analisa as materializações do PMCMV para as diferentes faixas de renda. Com base na Figura 2 é possível compreender o modo como o espaço urbano tem sido produzido pela política habitacional recente através da construção de novos conjuntos habitacionais na RMB.

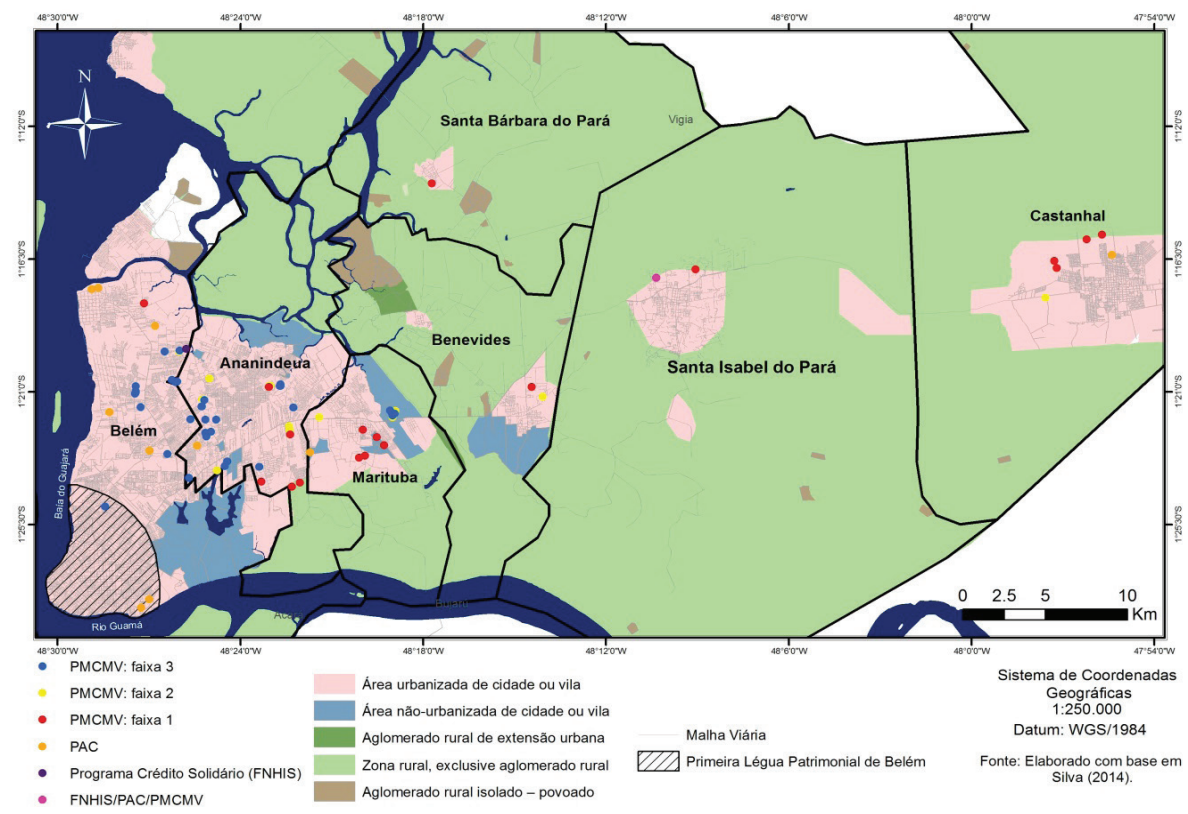

Figura 2. Localização dos diferentes conjuntos habitacionais construídos no contexto da politica recente (2003-2014) na Região Metropilitana de Belém.

Fonte: IBGE, 2010; Elaborado pelos autores. 
A localização dos conjuntos revela elementos importantes para se pensar a produção do espaço urbano, de modo que a natureza dos programas e fundos citados se materializa distintamente, traduzindo-se em contradições e conflitos. As localizações dos conjuntos expressam uma série de continuidades e descontinuidades, construindo a configuração espacial que marca pouco mais de uma década (2003-2014) de atuação dos agentes delimitados pela política habitacional recente na RMB.

Dentre as materializações, o PMCMV apresentou disparadamente a maior quantidade de conjuntos construídos, seguido de forma tímida pelo PAC. Por sua vez, o FNHIS esteve muito aquém das expectativas, revelando o esvaziamento do SNHIS frente ao lançamento do PAC e, sobretudo, do PMCMV. É válido frisar que “em 2009, o FNHIS foi direcionado para urbanização e a produção de novas moradias foi transferida para o Programa Minha Casa, Minha Vida" (CASTRO, 2013, p. 97). Nesse contexto, vários projetos do SNHIS foram incorporados ao PAC, assim como ao PMCMV. O maior exemplo dessas "migrações" de projetos foi a construção do conjunto Jardim das Garças, localizado em Santa Isabel do Pará. O Jardim das Garças I e II esteve vinculado ao FNHIS/PAC e o Jardim das Garças III ao PMCVM.

O PAC e em menor escala o FNHIS atuaram na construção de novas unidades habitacionais como parte das ações oriundas da urbanização de áreas precárias. Nesse contexto, destaca-se a construção de novas unidades habitacionais localizadas praticamente no mesmo local de origem, ou seja, não prevendo a remoção das famílias para áreas mais afastadas na periferia das cidades. Como exemplo desses conjuntos, pode-se citar a Comunidade Riacho Doce e o Residencial Liberdade, ambos situados no interior da Primeira Légua Patrimonial de Belém. Tais ações representam avanços em relação ao conjunto das materializações das políticas habitacionais que historicamente têm atuado via remoção das famílias para a periferia distante.

No que se refere à quantidade de conjuntos construídos, o PAC tem atuado de forma discreta se comparado ao PMCMV. No entanto, o PAC iniciou grandes obras como, por exemplo, a Comunidade Taboquinha, localizada no extremo norte de Belém, no distrito de Icoaraci. Trata-se da construção de 978 unidades habitacionais, compostas por apartamentos e casas destinadas às famílias que moravam em áreas precárias no interior do referido distrito. As unidades habitacionais da Comunidade Taboquinha ainda não foram entregues em sua totalidade (apenas 45\%), assim como outras intervenções do PAC como, por exemplo, a Comunidade Pantanal e a Comunidade Pratinha (apenas 20 unidades foram entregues das 350 previstas), sem contar com os empreendimentos em construção localizados no interior da Primeira Légua Patrimonial.

Diante desse cenário, nota-se que "as obras do PAC na RMB caminham a passos lentos (...) com problemas em relação à gestão, no que se refere ao repasse de recursos, cumprimento de prazos estipulados e demora na licitação de serviços, entre outros" (CASTRO, 2013, p. 159). Essa dinâmica contrasta nitidamente com as ações direcionadas no âmbito do PMCMV que ganham fôlego expressivo, com a construção de uma série de conjuntos habitacionais destinados às diferentes faixas de renda. Tais conjuntos são aprovados rapidamente, muitas vezes, dispensando os instrumentos de 
controle urbanístico de inclusão social e a gestão democrática, previstos no Plano Diretor. De fato, a ânsia e os interesses dos agentes privados que produzem esses conjuntos têm colocado em pauta velhas questões relacionadas à localização periférica dos conjuntos destinados aos segmentos de menor renda.

Nesse sentido, a lógica de localização dos conjuntos do PMCMV vem revelando antigas práticas espaciais que traduzem diferenciações sociais no espaço. Enquanto os conjuntos destinados às maiores faixas de renda se localizam em áreas relativamente bem situadas no interior da malha urbana, próximo às principais vias de circulação, os conjuntos da faixa 1 são construídos em áreas afastadas, de modo que as construtoras buscam os terrenos mais baratos, convertendo muitas vezes área rural em urbana, tal como era executado no período do BNH com o chamado "mercado popular".

As áreas "disponíveis” para a produção popular estão cada vez mais escassas e caras, sobretudo, em Belém e Ananindeua, forçando as construtoras a se direcionarem para setores mais afastados, quer seja em outros municípios ou até mesmo em áreas periféricas como, por exemplo, o bairro do Aurá, no extremo sul, limite da área urbana de Ananindeua onde já se observa a presença dos conjuntos Ananin (595 unidades habitacionais-casas) e Padre Pietro Gerosa (500 unidades habitacionais-apartamentos) (Figuras 3 e 4).
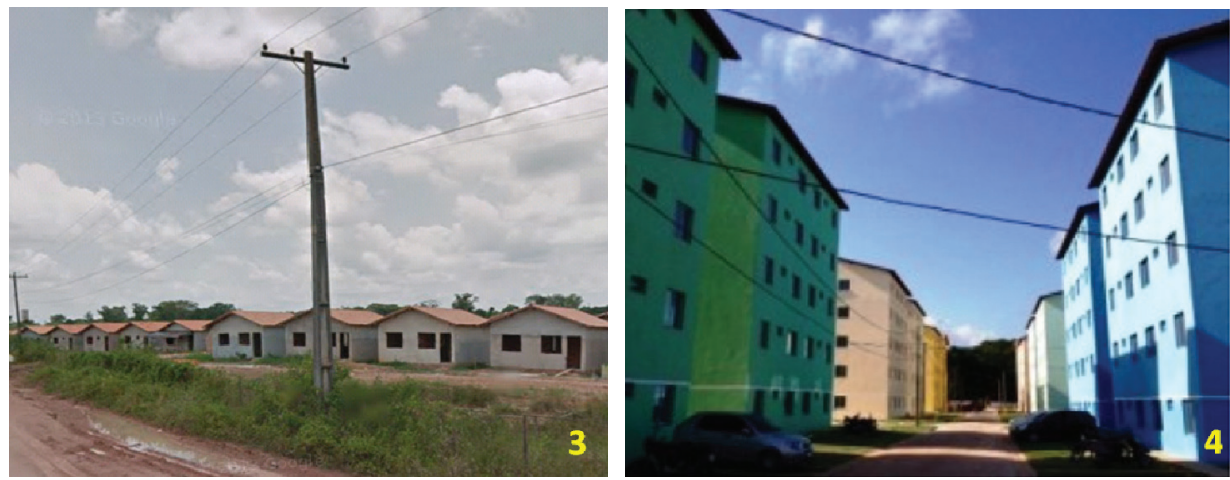

Figuras 3 e 4. Conjunto Ananin e Conjunto Padre Pietro Gerosa, respectivamente. Duas tipologias distintas do PMCMV (faixa 1), ambas localizadas no bairro do Aurá, no extremo sul de Ananindeua, limite da área urbana municipal.

Fonte: Trabalho de Campo, 2013.

No município de Castanhal, por exemplo, parece se repetir a lógica que ocorreu em Belém e Ananindeua, a partir da década de 1960, com a construção de grandes conjuntos habitacionais situados nas transições das áreas rurais e urbanas, revelando o peso da construção de conjuntos habitacionais na produção do espaço urbano. Como exemplo, pode-se citar o Conjunto Parque dos Castanhais (500 unidades habitacionais) (Figuras 5 e 6). 


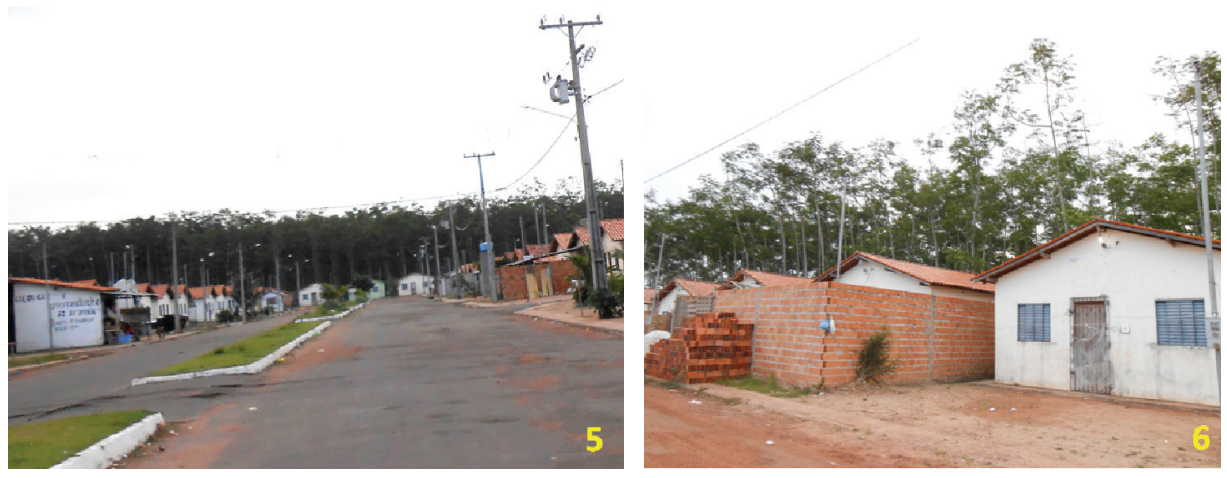

Figuras 5 e 6. Conjunto Parque dos Castanhais e seu entorno. Nota-se a presença de uma vasta área verde. Segundo a classificação dos setores censitários do IBGE 2010, o conjunto está situado na zona rural de Castanhal. A construção do conjunto, em 2011, revela de fato a produção do espaço urbano, modificando a natureza rural desta área.

Fonte: Trabalho de Campo, 2013.

A dificuldade em prover habitações na faixa de renda mais baixa do PMCMV fica evidente em alguns setores da RMB, sobretudo, quando se considera que a construção do primeiro conjunto habitacional em Belém (e até o presente momento o único) só foi anunciada 4 anos após do início do Programa. Trata-se do conjunto Jardim Maracá (550 unidades habitacionais-apartamentos), situado na Estrada do Outeiro, próximo à Estrada do Maracacuera, distrito de Icoaraci. O conjunto foi viabilizado pelo subprograma da Prefeitura Municipal de Belém, intitulado Viver Belém - Minha Casa Minha Vida, lançado pela Lei Municipal No 9014 de junho de 2013, prevendo, dentre outras coisas, a construção de conjuntos habitacionais populares no município. O programa apresenta arquitetura idêntica ao PMCMV no que se refere às três faixas de financiamento e abre caminho, também, para ações destinadas à provisão de conjuntos habitacionais para funcionários públicos.

O Conjunto Jardim Maracá tem estimativa de 15 meses para o término das obras, contados a partir da assinatura do contrato no dia 27 de julho de 2013. De fato, a partir desse programa, criam-se possibilidades de ações diferenciadas no âmbito do PMCMV, já que o Município de Belém pode entrar mais fortemente na provisão de conjuntos na faixa 1 .

Porém, considerando a lógica que tem se imposto na história da política habitacional, essa tendência é muito improvável, ainda mais quando se analisa a configuração espacial de Belém em que as áreas "disponíveis" na porção continental praticamente já se esgotaram, restando somente à porção insular que atualmente carece de infraestrutura. Nesse sentido, portanto, produzir conjuntos habitacionais nessas áreas sem dotá-las primeiramente de infraestrutura básica é repetir a lógica perversa que tem 
permeado as políticas habitacionais, relegando aos estratos sociais de menor renda as localizações periféricas, num nítido processo de segregação.

A análise do cenário que tem permeado a política habitacional recente (20032014) exige uma compreensão integrada entre habitação e espaço urbano. A construção de conjuntos habitacionais em determinadas localidades está inserida numa lógica mais ampla relacionada aos diferentes interesses e conflitos inerentes à produção do espaço urbano. $\mathrm{O}$ estudo na $\mathrm{RMB}$ revelou parcialmente essa complexidade na prática.

\section{Considerações Finais}

Neste trabalho discutiu-se a produção do espaço urbano tendo com base a reprodução de conjuntos habitacionais. Para tanto, realizou-se uma breve análise da trajetória seguida pela política habitacional brasileira. Nesse percurso, a ênfase foi atribuída à política habitacional recente, marcada inicialmente pela incorporação de um vasto aparato jurídico presente na Constituição de 1988 e na aprovação do Estatuto das Cidades que constituíram suportes à criação do Ministério das Cidades, à elaboração da nova Política Nacional de Habitação (PNH), lançada em 2004, e ao desenvolvimento do Plano Nacional de Habitação (PLANHAB), em 2008. A essa nova fase, acrescentou-se também a criação do Programa de Aceleração do Crescimento (PAC) e do Programa Minha Casa Minha Vida (PMCMV).

A lógica de produção de conjuntos habitacionais parece se repetir ao longo das políticas, sobretudo, no que se refere à localização periférica das habitações destinadas às demandas de menores rendimentos. Na busca por terrenos baratos, compatíveis com o preço dos imóveis para essa demanda, os conjuntos habitacionais são construídos muitas vezes em áreas rurais, afastadas dos principais setores de comércio e serviços, estendendo precariamente o tecido urbano.

Nesse debate, ressaltou-se que para a construção de habitações se exige a aquisição de um novo terreno a cada processo produtivo, dependendo, assim, intimamente do solo que não pode ser reproduzido e seu preço está relacionado à localização. Isso se traduz de modo conflituoso na produção do espaço urbano, de tal forma que enquanto os conjuntos destinados aos segmentos de menor renda historicamente têm se concentrado em áreas periféricas ou até mesmo rurais (preço do solo mais barato), os conjuntos destinados às faixas superiores têm sido construídos em áreas mais integrados à mancha urbana, ao longo das principais vias de circulação (preço do solo elevado).

Essa segmentação dos locais de moradia entre os que podem e os que não podem pagar mais pela habitação tem se repetido ao longo das políticas habitacionais, configurando um processo nítido de segregação no espaço urbano. Na política recente essa tônica já se mostra presente, sobretudo, no que se refere à produção de conjuntos pelo PMCMV, como se observou ao longo da análise empírica.

Observou-se, também, que os diferentes programas e fundos representativos da política habitacional recente (FNHIS, PAC, PMCMV) se materializaram em quantidades 
distintas, revelando tendências na RMB. O PMCMV apresentou o maior número de conjuntos habitacionais construídos, seguido timidamente pelo PAC. Já o FNHIS mostrou-se muito aquém das expectativas, sendo que alguns de seus empreendimentos "migraram" para o PMCMV em função das maiores "facilidades" de obtenção de recursos e aprovação de projetos.

O PMCMV esteve presente em todos os municípios da RMB, expressando grande dinamismo no contexto da política habitacional recente. Esse dinamismo, no entanto, se fez perversamente desconsiderando a legislação urbana e a gestão democrática. Quanto ao PAC, apesar da previsão de grandes obras de urbanização e de construção de unidades habitacionais, sua efetivação tem sido lenta, apresentando problemas de demora na licitação de serviços, no cumprimento de prazos, dentre outros.

Longe de se discutir de modo detalhado o desenvolvimento das políticas habitacionais, o presente trabalho teve como objetivo analisá-las do ponto de vista das suas materializações em conjuntos habitacionais. Nesse percurso, observou-se a íntima relação entre habitação e espaço urbano, de tal modo que pensar a construção de conjuntos habitacionais ao longo das políticas habitacionais requer a compreensão da dinâmica desse espaço, com suas contradições e conflitos. As diferentes localizações dos conjuntos habitacionais revelaram parte dessa dinâmica, contribuindo para a análise da produção do espaço urbano na RMB pela política habitacional recente.

\section{Referências}

AZEVEDO, S; ANDRADE, L. A. G. Habitação e poder: da Fundação da Casa Popular ao Banco Nacional de Habitação. Rio de Janeiro: Zahar Editores, 1982.

BONDUKI, N. Origens da habitação social no Brasil. Análise Social, São Paulo vol. XXIX(127), 1994. Disponível em: <http://www.ufpel.edu.br/faurb/prograu/documentos/ artigo1-habitacaosocial.pdf $>$. Acesso em: 12/12/2013.

. Política habitacional e inclusão social no Brasil: revisão histórica e novas perspectivas no governo Lula. Revista eletrônica de Arquitetura e Urbanismo, São Paulo, n.1, p. 71-104, set. 2008. Disponível em: <http://www.usjt.br/arq.urb>. Acesso em 12/11/2013.

BOTEGA, L. R. A política Habitacional no Brasil (1930-1990). Revela (Praia Grande). Ano I, n. 02.2008. Disponível em: $<$ http://www.fals.com.br/revela11/politicahabitacional. pdf>. Acesso em 9/01/ 2014.

CARDOSO, A. L. Programa Minha Casa Minha Vida está fora do Sistema de Habitação de Interesse Social. (entrevista para a FASE em 04/04/2009). Disponível em: <www. fase.org.br/v2/pagina.php?id=3108>. Acesso em 12/12/2013.

, et al. Habitação de interesse social: política ou mercado? Reflexos sobre a construção do espaço metropolitano. XIV Encontro Nacional da ANPUR. Rio de Janeiro, 2011. 
; ARAGÃO, T. A. Do fim do BNH ao Programa Minha Casa Minha Vida: 25 anos da política habitacional no Brasil. In. O Programa Minha Casa Minha Vida e seus efeitos territoriais. CARDOSO, A. L. (org.). Rio de Janeiro: Letra Capital, 2013.

; LAGO, L. C. O Programa Minha Casa Minha Vida e seus Efeitos Territoriais In. O Programa Minha Casa Minha Vida e seus efeitos territoriais. CARDOSO, A. L. (org.). Rio de Janeiro: Letra Capital, 2013.

CARLOS, A. F A. O espaço urbano: novos escritos sobre a cidade. São Paulo: Labur/ Edição Eletrônica, 2007. Disponível em < http://pt.scribd.com>. Acesso em 10/12/2013.

CASTRO, M. O. Os programas habitacionais de interesse social e sua atuação na Região Metropolitana de Belém: a espacialização das ações na contramão do direito à cidade. Dissertação (Mestrado). PPGEO/UFPA, 2013.

CORRÊA, R. L. O espaço urbano. São Paulo: Ática, 1989. (Série Princípios).

. Diferenciação sócio-espacial, escala e práticas espaciais. Cidades, Presidente Prudente. Vol. 4. n. 6, 2007.

FIX, M. A. B. Financeirização e Transformações Recentes no Circuito Imobiliário no Brasil. Tese (Doutorado), Instituto de Economia da Unicamp, 2011.

HOLANDA, A. C. G. A Nova política da habitação de interesse social no Pará (20072010): avanços e limites. Dissertação (Mestrado). NAEA/UFPA. 2011.

MARICATO, E. Por um novo enfoque teórico na pesquisa sobre habitação. São Paulo: Cadernos Metrópole (PUCSP), v. 21, p. 33-52, 2009. Disponível em <http://web. observatoriodasmetropoles.net>. Acesso em 24 abr. 2011.

. O impasse da Politica Urbana no Brasil. São Paulo: Editora Vozes, 2011.

MARTUCCI, R. Projeto tecnológico para edificações habitacionais: utopia ou desafio? São Paulo, 1990. 438p. Tese (Doutorado) - São Paulo: USP.

MINISTÉRIO DAS CIDADES. Os vereadores no processo de elaboração de Planos Diretores Participativos. Brasília, 2006.

OTERO, E. V. (2009). As Possibilidades e os Limites da Reabilitação de Conjuntos Habitacionais em São Paulo. Dissertação (Mestrado) em Arquitetura e Urbanismo Faculdade de Arquitetura e Urbanismo, Universidade de São Paulo, 2009. Disponível em: $\quad<$ www.teses.usp.br/teses/disponiveis/16/.../Dissertacao_EstevamOtero.pdf $>$. Acesso em: 15/01/2013.

GOVERNO DO ESTADO DO PARÁ. Plano Estadual de Habitação de Interesse Social (PEHIS), 2009. Disponível em: < http://www.idesp.pa.gov.br/pdf/artigos/ pehisdiagnosticohabitacional.pdf $>$. Acesso em: 12/01/2014.

RIBEIRO, L. C. Q; PECHAMN, R. M. O que é questão de moradia. Nova Cultural / Brasilienses, 1985. (Coleção Primeiros Passos: 65).

RODRIGUES, A. M. Moradia nas cidades brasileiras. São Paulo: Editora Contexto, 2003. (Repensando a Geografia). 
SARGES, M. N. Belém: riquezas produzindo a belle-époque (1870-1912). Belém: Pakatatu, 2002.

SANTOS, M. Técnica, espaço, tempo: globalização e meio técnico-científicoinformacional. São Paulo: Hucitec, 1994.

SILVA, M. L. Habitação produzindo espaço urbano na reprodução de conjuntos habitacionais: experiências e tendências na Região Metropolitana de Belém. Dissertação (Mestrado). PPGEO/UFPA, 2014.

SILVEIRA, L. R. Cidade, corporação e periferia urbana: acumulação de capital e segregação espacial na (re) produção do espaço urbano. Santa Cruz do Sul: EDUNISC, 2003.

SHIMBO, L. Z. Habitação social, habitação de mercado: a confluência entre Estado, empresas construtoras e capital financeiro. Tese (Doutorado). Escola de Engenharia de São Carlos, São Paulo, 2010.

VILLAÇA, F. O que todo cidadão precisa saber sobre habitação. São Paulo: Global Editora, 1986. (Cadernos de Educação Política, n. 16).

$$
* * *
$$

Este trabalho é resultante da Dissertação de Mestrado apresentada ao Programa de PósGraduação em Geografia da Universidade Federal do Pará (PPGEO/UFPA), defendida em maio de 2014.

Marlon Lima da Silva

Licenciado, Bacharel e Mestre em Geografia pela Universidade Federal do Pará (UFPA). Atualmente é Professor Substituto da Faculdade de Geografia e Cartografia (FGC/UFPA) e Técnico em Gestão de Desenvolvimento Urbano na Secretaria de Estado de Desenvolvimento Urbano e Obras Públicas (SEDOP) Travessa do Chaco, 2158, Marco- CEP 66093-410 - Belém, PA - Brasil. E-mail: marlon.angelim@yahoo.com.br

Janete Marília Gentil Coimbra de Oliveira

Doutora em Geografia Humana pela Universidade de São Paulo (USP). Realizou pós-doutorado na área de Geografia Urbana na Universidad de Barcelona (UB), Espanha. Professora Associada IV aposentada, tendo atuado na Faculdade de Geografia e Cartografia e no Programa de Pós-Graduação em Geografia (PPGEO/ UFPA) - Rua Augusto Corrêa, 01, Guamá - CEP 66075-110 - Belém, PA - Brasil. E-mail: jangencom@hotmail.com 